\title{
In vitro production of tropane alkaloids from Brugmansia suaveolens
}

\author{
Tijen Talas Ogras ${ }^{\left({ }^{*},\right.}$ Elif Tahtasakali2, Selma Ozturk ${ }^{(D)}$
}

${ }^{1}$ TUBITAK, Marmara Resarch Center, Genetic Engineering and Biotechnology Institute, Gebze, Kocaeli, Turkiye

${ }^{2}$ TUBITAK, Marmara Research Center, Materials Institute, Gebze, Kocaeli, Turkiye

\begin{abstract}
For thousands of years, secondary metabolites have been utilized as medications, flavors, pesticides, and dyes. For the generation of valuable secondary metabolites, in vitro plant culture techniques have been viewed as beneficial alternatives to whole plants. Brugmansia suaveolens is an ornamental plant including anticholinergic agents which are employed in medicine. Callus induction was performed from leaf and internode explants cultured on Murashige and Skoog's medium supplemented with different concentrations and combinations of plant growth regulators (PGRs) with 6 treatments. The highest callus induction response was obtained from the leaforiginated explants $(73 \%)$ on the medium supplemented with $0.4 \mathrm{mg} / \mathrm{L} \mathrm{KIN}$ and $0.2 \mathrm{mg} / \mathrm{L}$ NAA which produced friable callus in 4 weeks. The cell suspension culture of $B$. suaveolens was established in shake flasks using friable calli. The extraction protocol of tropane alkaloids was optimized, atropine and scopolamine were obtained efficiently. The data could provide technical support for the large-scale production of valuable alkaloids of $B$. suaveolens in vitro systems with improved strategies.
\end{abstract}

\section{ARTICLE HISTORY}

Received: May 07, 2021

Revised: Jan., 06, 2022

Accepted: Jan., 30, 2022

\section{KEYWORDS}

Brugmansia suaveolens L.,

Atropine,

Callus,

Scopolamine,

Suspension culture.

\section{INTRODUCTION}

Plants have a diverse group of well-recognized phytochemicals which are named as secondary metabolites. Secondary metabolites have been used as drugs, flavors, insecticides, and dyes for thousands of years. The applications of in vitro plant culture techniques have been seen as beneficial alternatives to whole plants for the production of valuable secondary metabolites (Baque et al., 2012). The secondary metabolites are being extracted efficiently from plants as their chemical synthesis is complex and requires expensive instrument use. However, large amounts of plant materials are needed for the extraction of secondary metabolites. Unfortunately, the collection of plants from their natural habitats threatens the existence of different types of living organisms and environments (Kumar and Gupta, 2008). Production of the secondary metabolites by plant tissue culture system could be accomplished efficiently using callus, cell suspension, and organ (embryo, root, and shoot) cultures. The following are

\footnotetext{
*CONTACT: Dr. Tijen Talas Oğraş $\bigotimes$ tijen14@gmail.com; tijen.ogras@tubitak.gov.tr Marmara Research Center, 41470 Gebze, Kocaeli, Turkiye 
some of the benefits of in vitro plant culture systems for the generation of secondary metabolites:

1) Whole plant and organs can be produced under controlled conditions independently of external factors (eg., climate, soil content);2) Controlled plant cell and tissue cultures can yield a source of defined standard phytochemicals in large volumes with improved quality; 3) Cultured plant cells would be free of microbes.

Several in vitro plant cell culture applications have been performed for large-scale production of secondary metabolites to produce higher amounts than in intact plants (Ikeuchi et al., 2013; Chandran et al., 2020). Many reports have described that some approaches have been applied to increase their productivity. Shoot cultures of Bacopa monnieri were established for the production of bacoside A by Praveen et al., (2009) and when compared to field-grown plants, the regenerated shoots had a 3 -fold increase in bacoside A content. Similarly, in vitro regenerated shoots of Nothapodytes nimmoniana yielded higher amounts of camptothecin when compared to their mother plants (Dandin \& Murthy, 2012).

The accumulation of secondary metabolites is improved by some strategies such as transformation, elicitor treatment, mutagenic chemical, and bioreactor use. The scaling up of the tropane alkaloid anisodamine in hairy root cultures of two ecotypes of Brugmansia candida plants by rolC gene expression was achieved (Cardillo et al., 2013). The release of scopolamine and hyoscyamine into the media after elicitor treatment of B. candida roots was previously documented in a study (Pitta-Alvarez et al., 2000). In addition, special bioreactor systems have been devised for the large-scale cultivation of plant cells for the production of bioactive compounds with efficient applications.

Alkaloid group is currently used in medicine and this group includes the analgesics morphine and codeine, the anticancer agent vinblastine, the gout suppressant colchicine, and the sedative scopolamine. Tropane alkaloid group is a typical secondary metabolite of certain Solanaceous genera including Atropa, Hyoscyamus, Duboisia, Scopolia, and Mandragora. Tropane alkaloids are a unique group of compounds that are commonly employed as parasympathetic nervous system blockers. They are known to prevent the binding of acetylcholine to its receptor and as a result have effects on heart rate, respiration, and functions in the central nervous system (anticholinergic poisoning). Atropine and scopolamine are the major alkaloids in Solanaceae family plants. It is reported that tropane alkaloid content is different in the tissues and development stages of plants (Ghorbanpour et al., 2013). Atropine is a well-known tropane alkaloid and is used for treating organophosphate poisoning and exposure to some chemical weapons. Scopolamine (sometimes called hyoscine) is a pharmacological drug that is used to treat nausea, vomiting, motion sickness, and smooth muscle spasms. Scopolamine has a tenfold higher commercial demand than atropine. Scopolamine was also suggested as a protective metabolite of B. suaveolens against insects (Alves et al., 2007; Sarin, 2005).

Many efforts have been undertaken to improve practical tropane alkaloids production methods using plant tissue culture techniques (Dehghan et al., 2012). A variety of Solanaceous plants have been examined for the production of medically important alkaloids through callus, suspension, and hairy root cultures (Pitta-Alvarez et al., 2000; Cardillo et al., 2010; Chandran et al., 2020).

B. suaveolens is an ornamental plant known as angel trumpet. It is a member of Solanaceae family and is considered toxic with some medical properties. B. suaveolens produces atropine, scopolamine, and hyoscyamine alkaloids as defense molecules which are organic esters exhibiting hallucinogenic, antispasmodic, diaphoretic, and diuretic activities (Pitta-Alvarez et al., 2000; Anthony et al., 2009). In vitro tropane alkaloid production of Brugmansia species is carried out in a few scientific works and they are mostly performed with hairy root cultures. 
The main objective of this study was to establish optimal in vitro culture conditions by using different combinations of PGRs. Also, an efficient extraction protocol of tropane alkaloids was optimized, and the presence of scopolamine and atropine was determined qualitatively.

\section{MATERIAL and METHODS}

\subsection{Plant Material and Seed Germination}

Mature seeds of B. suaveolens were collected in September of 2019 in Gebze, Kocaeli, Turkey and a voucher specimen was deposited. The seeds were immersed in water for one hour and the seed coat was removed gently. The seed surface sterilization was performed in $70 \%(\mathrm{v} / \mathrm{v})$ ethanol for $2 \mathrm{~min}$ and in $50 \%(\mathrm{v} / \mathrm{v})$ commercial bleaching $(5.25 \% \mathrm{w} / \mathrm{v}$ solution of sodium hypochlorite) including Tween 20 (two drops for $100 \mathrm{ml}$ solution) for $10 \mathrm{~min}$. Then the seeds were rinsed four times in sterile distilled water. The disinfected seeds were blotted with sterile filter paper and cultured on PGR free Murashige Skoog (MS) (1962) basal medium containing $3 \%$ sucrose $(\mathrm{w} / \mathrm{v})$ and $0.6 \%$ agar $(\mathrm{w} / \mathrm{v})$ with $\mathrm{pH} 5.8$. The seeds were incubated at $25 \pm 2{ }^{\circ} \mathrm{C}$ with a relative humidity of 55-60\% under dark for two weeks. Then, the cultures were transferred to $16 \mathrm{~h}$ light $/ 8 \mathrm{~h}$ dark photoperiod conditions by cool white fluorescent lamps with an intensity of 3000 lux.

\subsection{Establishment of Callus and Cell Suspension Cultures}

Calli were induced from leaf and internode (epicotyl and hypocotyl pieces) explants of 8 weeks old in vitro germinated seedlings of $B$. suaveolens. The leaf pieces with $0.5 \mathrm{~m}^{2}$ and the internodes with $1 \mathrm{~cm}$ length were excised from the seedlings and were placed on full-strength semisolid MS basal media. The media were supplemented with a synthetic auxin and different combinations of auxins and cytokinins including; 2,4-dichlorophenoxyacetic acid (2,4-D), naphthalene acetic acid (NAA), benzyl aminopurine (BAP), indole-3-acetic acid (IAA), thidiazuron (TDZ) and kinetin (KIN).

The explants were placed on $90 \mathrm{~mm}$ petri dishes for callus development. Normally, plants are subjected to variable stresses in vitro culture systems. Considering the stress effects of plant tissue culture systems, concentrations of PGRs were used in minimal amounts in the culture media of $B$. suaveolens. The PGR free MS basal medium was used as a control treatment. In addition, one set of the treatments of the cultures were incubated under dark. The frequency of callus induction on semisolid MS medium was calculated according to the following equation:

$$
\text { Callus induction frequency }(\%)=\frac{\text { The number of calli formation }}{\text { Total number of explant used }} \times 100
$$

Following the callus formation on the edges and at the tips of the explants, the induced calli were dissected from the explants and transferred onto the same ingredients containing fresh medium for the subsequent 4 weeks. The calli were harvested from the second passage of cultures and co-cultivated on semisolid MS media for the fourth passage where the assessment of the 6 treatments was performed to find out the effective experimental design for callus growth of $B$. suaveolens. Inoculum weight of callus for fourth subculturing was $1.0 \pm 0.05 \mathrm{~g}$ as initial fresh weight $\left(\mathrm{FW}_{\text {initial }}\right)$.

Cell suspension cultures of B. suaveolens were initiated by transferring fourth-round subcultures of leaf-derived, friable calli into liquid MS3 medium (containing $0.4 \mathrm{mg} / \mathrm{L} \mathrm{KIN}+0.2$ $\mathrm{mg} / \mathrm{L}$ NAA). The best cell growth performance of the suspension cultures was observed with the MS3 medium. Two sizes of flasks (100 and $250 \mathrm{ml})$ were used with different volumes $(1 / 8$ and 1/5) of the growth media. Erlenmeyer flasks of $100 \mathrm{ml}$ and $250 \mathrm{ml}$ sizes were filled with $1 / 5$ and 1/8volume of liquid MS3 growth medium. The flasks with $100 \mathrm{ml}$ size were filled with $12.5 \mathrm{~m}$ and $20 \mathrm{ml}$ and the culture flasks with $250 \mathrm{ml}$ size were filled $31.25 \mathrm{ml}$ and $50 \mathrm{ml}$ of the growth medium. Actively growing friable calli clumps were selected for suspension culture 
starting material. The callus clumps were slightly chopped with a scalpel and cell suspension culture was inoculated with $1.0 \pm 0.05 \mathrm{~g}$ of calli biomass $\left(\mathrm{FW}_{\text {initial }}\right)$ to initiate suspension cultures.

The inoculated flasks of the suspension cultures were placed on a rotary orbital shaker at 100 rotations per minute and incubated under the same photoperiod, temperature, and humidity conditions as the callus cultures. The culture medium was refreshed with a new liquid medium at the end of 2 weeks, and the suspension cultures were maintained for 4 weeks.

\subsection{Assessment of the Culture Growth}

After 30 days of fourth cultivation in liquid MS medium, the calli were morphologically assessed and final fresh weight (FW) was obtained. Cell growth of the cultures was expressed as FW, dry weight (DW), and growth index (GI). Rating of callus was also evaluated as callus score by size between 1-7 mm.

The calli were washed with distilled water and were blotted on tissue paper at the end of cell suspension culture period of 4 weeks. The FW of the proliferated calli was obtained by weighing. The callus and the cell suspension culture biomass were oven-dried at $40^{\circ} \mathrm{C}$ for $24 \mathrm{~h}$ and DW was obtained. The growth of the cultures was represented as GI by using the equation given below.

$$
\mathrm{GI}=\frac{\text { (Final fresh weight of biomass }- \text { Initial fresh weight of inoculum) }}{\text { Initial fresh weight of inoculum }}
$$

\subsection{Tropane Alkaloid Extraction from Plant Material}

Tropane alkaloid extraction was carried out from $4^{\text {th }}$ subcultured callus cultures and leaf samples. The leaf material was collected from the natural habitat in flowering time. The dried samples ( $5 \mathrm{~g} \mathrm{DW}$ ) were ground to fine powder by using a grinder and alkaloid extraction was performed as described by Kamada et al., (1986) with some modifications. Briefly, an appropriate volume of extraction buffer $\mathrm{CHCI}_{3} / \mathrm{MeOH} / \mathrm{NH}_{4} \mathrm{OH}(\mathrm{I} / 5 / 1)$ was added onto the powdered materials, and the mixture was sonicated in an ultrasonic water bath for $10 \mathrm{~min}$. The slurry was macerated for 24 hours at room temperature. The crude extract was filtered through filter paper, washed twice with chloroform $(\mathrm{CHCl} 3)$, and evaporated. The residue was dissolved in $2 \mathrm{ml}$ of sulfuric acid $(98 \% \mathrm{v} / \mathrm{v})$ and $5 \mathrm{ml}$ of CHCI3 to separate $\mathrm{CHCI} 3$ phase. The aqueous phase was adjusted to $\mathrm{pH} 10$ with $25 \%$ ammonium hydroxide $(\mathrm{NH} 4 \mathrm{OH})$ solution in the ice bucket. Alkaloid residue was extracted twice with $\mathrm{CHCI}_{3}$ and filtered by adding anhydrous $\mathrm{Na}_{2} \mathrm{SO}_{4}$ under vacuum at $40^{\circ} \mathrm{C}$.

\subsection{Qualitative Analyses of Tropane Alkaloids}

Qualitative estimation of the alkaloid content of $B$. suaveolens leaf extract was carried out using thin-layer chromatography (TLC) on silica gel alumina TLC plates $(20 X 20 \mathrm{~cm}$ Silica gel 60 $\mathrm{F}_{254}$ plates). The alkaloid leaf extract of $B$. suaveolens and alkaloid standards of atropine and scopolamine were spotted onto the silica plate. The separation of the spots was performed on the plate using solvent systems of chloroform/acetone/ammonia: methanol (3/17) with a combination of 5/4/1 as mobile phase. Following the separation, the spots were visualized under short and long-wavelength ultraviolet lights $(254$ and $365 \mathrm{~nm})$ and immediately the plate was sprayed with Dragendorff's Reagent to clarify the spots of tropane alkaloids.

The alkaloid extracts of the callus and the leaf samples and atropine standard (SigmaAldrich) were analyzed by High-Performance Liquid Chromatography (HPLC) system (Shimadzu) equipped with a Zorbax Extend C18 column (100x4,6 mm, 3,5 $\mu \mathrm{m}$ particle size) and a UV-VIS detector. The data series of standard atropine dilutions over a range of $150-$ $6555 \mu \mathrm{g} / \mathrm{ml}$ were used to construct a calibration graph by plotting the peak area versus the corresponding concentration. 
The samples were filtered through a $0.45 \mu \mathrm{m}$ membrane prior to the HPLC assay. The mobile phase was optimized with potassium acetate/acetonitrile $(82 / 18, \mathrm{v} / \mathrm{v}, \mathrm{pH} 3.5)$ with a flow rate of $1 \mathrm{ml} \cdot \mathrm{min}^{-1}$ at $40^{\circ} \mathrm{C}$ and total analysis time was $10 \mathrm{~min}$. The injection volume of the samples was set at $10 \mu \mathrm{l}$ and elution was monitored at $210 \mathrm{~nm}$ (Koetz et al., 2017).

\subsection{Statistical Analyses}

Experimental designs of the callus and the cell suspension cultures were repeated four times with a sample size of 6 replications. The influence of the experimental designs was analysed by one-way analysis of variance (ANOVA) to detect significant differences between the means of the data. All the treatments were conducted in a randomized design.

\section{RESULTS}

\subsection{Plant Material and Seed Germination}

The uncoated seeds of $B$. suaveolens were germinated on PGR free semisolid MS basal medium with $80 \%$ germination rate (Figure 1). The seed germination of B. suaveolens was evaluated using different chemical treatments by Montanucci et al. (2012). They found that the seed germination was reduced to various extents by physical and chemical treatments.

Figure 1. In vitro germination of B. suaveolens seeds on MS basal medium after 14 days (Scale bar: 1 $\mathrm{cm})$.

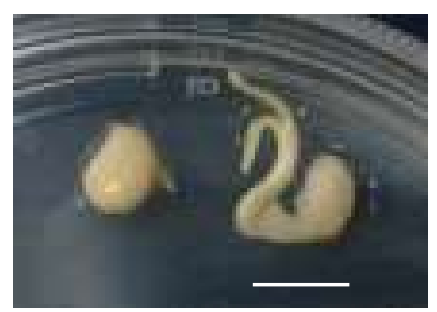

\subsection{Establishment of Callus and Cell Suspension Cultures}

In the present work, in vitro culture system leading to the induction of callus was initiated from the internode and the leaf explants of 8 weeks old in vitro raised seedlings of $B$. suaveolens. Different PGRs were used either singly or in combination (Table 1) to evaluate their influences on callus induction.

Table 1. Effects of different PGR treatments on callus induction from internode and leaf explants of $B$. suaveolens after 6 weeks of cultivation.

\begin{tabular}{|c|c|c|c|c|c|}
\hline \multirow[b]{2}{*}{ Treatment } & \multirow[b]{2}{*}{ PGR (mg/L) } & \multicolumn{2}{|c|}{ Internode derived } & \multicolumn{2}{|c|}{ Leaf derived explant } \\
\hline & & $\begin{array}{l}\text { Callus } \\
\text { morphology }^{* *}\end{array}$ & $\begin{array}{l}\text { Callus } \\
\text { score }^{*}\end{array}$ & $\begin{array}{c}\text { Callus } \\
\text { morphology }\end{array}$ & $\begin{array}{l}\text { Callus } \\
\text { score }^{*}\end{array}$ \\
\hline MS0 & PGR free MS & $\mathrm{DG}, \mathrm{B}, \mathrm{c}$ & + & $\mathrm{G}, \mathrm{DG}, \mathrm{B}, \mathrm{c}$ & + \\
\hline MS1 & $2,4-\mathrm{D}(0.5)$ & $\mathrm{L}, \mathrm{f}, \mathrm{r}$ & ++ & $\mathrm{WG}, \mathrm{f}, \mathrm{r}$ & ++ \\
\hline MS2 & $2,4-\mathrm{D}+\operatorname{Kin}(0.2+0.5)$ & $\mathrm{W}, \mathrm{L}, \mathrm{f}$ & ++ & $\mathrm{G}, \mathrm{LG}, \mathrm{f}, \mathrm{g}$ & ++ \\
\hline MS3 & Kin+NAA $(0.4+0.2)$ & $\mathrm{LG}, \mathrm{f}, \mathrm{g}$ & +++ & $\mathrm{LG}, \mathrm{f}, \mathrm{g}$ & +++ \\
\hline MS4 & $\mathrm{BAP}+\mathrm{NAA}(0.5+0.5)$ & $\mathrm{L}, \mathrm{g}$ & + & WG, g & + \\
\hline MS5 & $\mathrm{BAP}+2,4-\mathrm{D}+\mathrm{Kin}(0.5+0.2+0.5)$ & $\mathrm{L}, \mathrm{G}, \mathrm{c}$ & ++ & WG, G, co & ++ \\
\hline MS6 & TDZ+IAA $(0.1+0.1)$ & $\mathrm{L}, \mathrm{WG}, \mathrm{c}$ & ++ & $\mathrm{G}, \mathrm{WG}, \mathrm{c}$ & ++ \\
\hline
\end{tabular}

${ }^{*}$ Callus formation: (+) weak ( $1 \mathrm{~mm}$ diameter), $(++)$ moderate (up to $4 \mathrm{~mm}$ diameter), (+++) good (up to $7 \mathrm{~mm}$ diameter).

${ }^{* *}$ Colour; Whitish (W), Light green (L), Yellowish (Y), Green (G), Lush green (LG), Dark green (DG), Brownish

(B) and form; Friable (f), Globular (g), Compact (c), Root formation (r), Cotton like (co). 
Callogenic response of the explants was observed in the second week through the swelling of the explants on 6 different MS media. Subsequently, the formation of friable and compact calli forms was observed at the cut tips of internode sticks and on the edges of the leaves. Callogenesis was observed on both types of explants with different morphology and growth rate. The best response of callus formation was observed with friable and green calli of the leaf explants. The leaf explants exhibited the highest frequency of callus induction (73\%) which was greater than that obtained in the internode explants (59\%). Callus induction of the explants has also been performed under the dark. The highest callus induction frequency was obtained $(55 \%)$ with the leaf explants compared to the induction frequency of internode explants $(45 \%)$ under dark. Generally, the induced calli were observed as light yellow and the color turned brownish after two weeks under dark.

It is obvious that the callogenesis process of $B$. suaveolens was positively affected under photoperiod conditions. The light was beneficial for the production of callus and cell suspension cultures compared to dark. The effects of different PGR on callus induction were assessed based on callus morphology and callus score after 6 weeks of culturing of the explants (Table 1). The appearance of the calli was observed as friable, globular, compact, root forming, and cottonlike. The color of the calli was various on different growth media. The callus score was also evaluated based on the diameter of the propagated callus.

\subsection{Assessment of the Culture Growth}

Assessment of the 6 treatments was performed for callus propagation using the fourth subculture as callus score, FW, DW, and GI as shown in Table 2.

Table 2. Effects of different PGR treatments on callus growth of $3^{\text {rd }}$ cultivation of leaf-derived explants of $B$. suaveolens after 4 weeks.

\begin{tabular}{llllllc}
\hline Treatment & PGR (mg/L) & \multicolumn{1}{c}{$\begin{array}{c}\text { Callus } \\
\text { morphology }\end{array}$} & $\begin{array}{c}\text { Callus } \\
\text { score* }\end{array}$ & $\begin{array}{c}\mathrm{FW}^{* *} \\
\text { (gr/culture })\end{array}$ & DW (g) & $\begin{array}{c}\text { Growth } \\
\text { Index } \\
(\mathrm{GI})\end{array}$ \\
\hline MS0 & PGRs free MS & Dark green, compact & + & $1.42 \pm 0.19$ & $0.12 \pm 0.01$ & 0.42 \\
\hline MS1 & $2,4-\mathrm{D}(0.5)$ & Whitish, root form & ++ & $2.62 \pm 0.30$ & $0.19 \pm 0.01$ & 1.62 \\
\hline MS2 & $\begin{array}{l}2,4-\mathrm{D}+\mathrm{Kin} \\
(0.2+0.5)\end{array}$ & Green, semi friable & ++ & $3.38 \pm 0.27$ & $0.32 \pm 0.01$ & 2.38 \\
& $\begin{array}{l}\text { Kin+NAA } \\
(0.4+0.2)\end{array}$ & $\begin{array}{l}\text { Lush green, friable, } \\
\text { globular }\end{array}$ & +++ & $3.92 \pm 0.29$ & $0.37 \pm 0.00$ & 2.92 \\
\hline MS3 & $\begin{array}{l}\text { BAP+NAA } \\
(0.5+0.5)\end{array}$ & Whitish, loose & + & $1.61 \pm 0.41$ & $0.09 \pm 0.01$ & 0.61 \\
\hline MS4 & $\begin{array}{l}\text { BAP+2,4-D+Kin } \\
(0.5+0.2+0.5)\end{array}$ & $\begin{array}{l}\text { Whitish, cottony, } \\
\text { leaf }\end{array}$ & ++ & $1.15 \pm 0.21$ & $0.06 \pm 0.01$ & 0.15 \\
\hline MS5 & $\begin{array}{l}\text { TDZ+IAA } \\
(0.1+0.1)\end{array}$ & Greenish, compact & ++ & $2.04 \pm 0.32$ & $0.16 \pm 0.01$ & 1.04 \\
\hline MS6 & & & & & \\
\hline
\end{tabular}

${ }^{*}(+)$ weak (1 $\mathrm{mm}$ diameter), (++) moderate (up to $4 \mathrm{~mm}$ diameter), $(+++)$ good (up to $7 \mathrm{~mm}$ diameter)

${ }^{* *} \mathrm{FW}$ : Fresh weight final. Callus inoculum: $1 \mathrm{~g} /$ culture. Data represent mean values $( \pm S E)$ of three repeats each with six replicates. Level of significance $p<.05$.

Compact, dark green, and small (around $1 \mathrm{~mm}$ diameter) callus forms were observed on the PGR free MS medium (MS0) after 2 weeks of cultivation, and the cultures became brownish after 4 weeks of cultivation. Interestingly, a transition state was observed where some tiny leaf structures formed on some explants after 5 weeks on PGR free MS medium. 2,4-D is the most often used synthetic auxin for callus induction with fast-growing calli. While the explants of $B$. 
suaveolens were cultured on MS1 medium supplemented with $0.5 \mathrm{mg} / \mathrm{L}$ 2,4-D, light green, friable calli formation were observed under photoperiod conditions. In addition, distinctly different morphology root formation was observed on some callus aggregates after the fourth subculturing on MS1 media (Figure 2a). In addition, the calli became necrotic after 4 weeks when subcultured on the medium containing 2,4-D. Combinations of auxins and cytokinins produced more callus than auxin alone, according to our findings. It is reported that 2,4-D amounts ranging from $1.0 \mathrm{mg} / \mathrm{L}$ to $3.0 \mathrm{mg} / \mathrm{L}$ in the culture medium resulted in a high degree of browning of callus after 3 weeks (Dong et al., 2015). Liu et al. (2018) performed a study with miniature rose that 3.0 to $5.0 \mathrm{mg} / \mathrm{L} 2,4-\mathrm{D}$ concentration caused high degree browning of callus and abnormal embryo appearances. In order to reduce the inhibitory effect of 2,4-D, it is advised not to use high concentrations in the callus induction process. Importantly, browning is causing cell death by affecting cell growth in plant tissue culture (Dong et al., 2015; Sarin, 2005). The browning of callus was observed after extended periods of the culture.

Figure 2. The morphology of leaf-derived calli of $B$. suaveolens on different semisolid media after 4 weeks of cultivation, (a) Root forming callus on MS1 medium, (b) Callus on MS3 medium, (c) Callus on MS4 medium, (d) Callus on MS5 medium. (Scale bars: $1 \mathrm{~cm}$.)
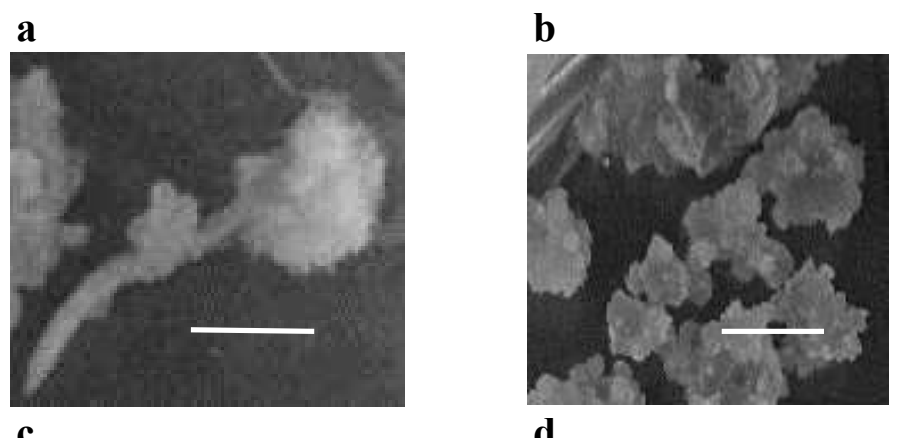

c

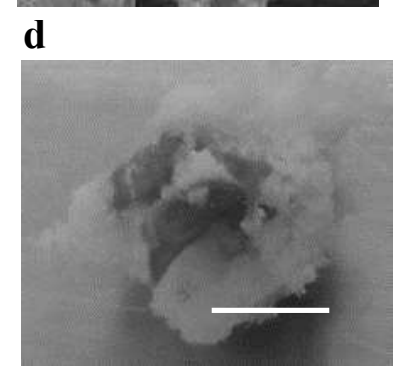

The highest values of FW (3.92 $\pm 0.29 \mathrm{~g})$, DW $(0.37 \pm 0.00 \mathrm{~g})$, and GI (2.92) data were obtained in a combination of the semisolid MS3 medium supplemented with $0.4 \mathrm{mg} / \mathrm{L} \mathrm{KIN} \mathrm{+}$ $0.2 \mathrm{mg} / \mathrm{L}$ NAA. The MS3 treatment produced friable and lush green calli (Figure $2 \mathrm{~b}$ ). Based on the mean of FW $(3.38 \pm 0.27 \mathrm{~g})$ and GI (2.389) data, the MS2 treatment $(0.2 \mathrm{mg} / \mathrm{L} 2,4-\mathrm{D}+0.5$ $\mathrm{mg} / \mathrm{L} \mathrm{KIN}$ ) provided an efficient callogenesis after the MS3 treatment. Montanucci et al. (2012) performed callus induction and plant regeneration studies of $B$. suaveolens with different combinations of 2,4-D and KIN and they obtained $66 \%$ callus induction with $0.5 \mathrm{mg} / \mathrm{L} \mathrm{2,4-} \mathrm{D}$ $+0.5 \mathrm{mg} / \mathrm{L}$ KIN combination on MS medium.

MS4 treatment has a combination of $0.5 \mathrm{mg} / \mathrm{L} \mathrm{BAP}+0.5 \mathrm{mg} / \mathrm{L} \mathrm{NAA}$ resulting in formation of whitish, loose callus forms (Figure 2c) and 1.61 $\pm 0.41 \mathrm{~g} \mathrm{FW}$ was recorded in 4 weeks of cultivation. However, previously a study was performed by our group using BAP and NAA supplemented media for callus induction of Hyoscyamus niger. The media containing 0.25 $\mathrm{mg} / \mathrm{L} \mathrm{BAP}+0.25 \mathrm{mg} / \mathrm{L} \mathrm{NAA}$ and $0.5 \mathrm{mg} / \mathrm{L} \mathrm{BAP}+0.5 \mathrm{mg} / \mathrm{L} \mathrm{NAA}$ performed friable, green callus formation with leaf and stem explants of $H$. niger which is a member of the Solanaceae family. 
The effect of MS6 medium supplemented with $0.1 \mathrm{mg} / \mathrm{LTDZ}+0.1 \mathrm{mg} / \mathrm{LIAA}$ promoted light green, compact callus formation. Cultivation of the leaf-derived calli on MS6 medium resulted in $2.04 \pm 0.32 \mathrm{~g} \mathrm{FW}$ and $1.04 \mathrm{GI}$ at the end of 4 weeks. The calli became brown on MS6 medium when the cultivation prolonged more than 4 weeks.

The lowest callus FW $(1.15 \pm 0.21 \mathrm{~g})$ was obtained on the treatment of MS5 medium ( 0.5 $\mathrm{mg} / \mathrm{LBAP}+0.2 \mathrm{mg} / \mathrm{L} 2,4-\mathrm{D}+0.5 \mathrm{mg} / \mathrm{LKIN})$. MS5 medium was poor at propagating standard callus forms like other calli-forming media. In MS5 medium is caused to produce cotton-like cotton-like white tissue forms (Figure 2d) with some tiny leaves in some callus aggregates. Because of the cotton-like calli appearance and leaf formation in some callus aggregates, FW and GI data of this treatment were not included in the statistical analyses.

The cell inoculum size was used $1.0 \pm 0.05 \mathrm{~g}$ /culture for callus and cell suspension cultures of $B$. suaveolens. Inoculum size is an important parameter on cell growth and has a positive effect on the metabolite yield of cell suspension cultures. A suitable inoculum size can provide higher biomass production and accumulation of secondary metabolites. Lee and Shuler (2000) studied the effect of cell inoculum density on ajmalicine production of Catharanthus roseus cells. The study's findings revealed that increasing inoculum density resulted in higher ajmalicine concentrations. However, high inoculum size could be growth limiting in vitro cultures because of the accumulation of cell metabolites, toxic products, dead cells, and oxygen depletion during the stationary phase. It is also reported that a higher inoculum size does not produce high cell biomass. The suspension culture media were refreshed at the $15^{\text {th }}$ day and the cultures were terminated after 30 days of culturing under photoperiod conditions. Cell aggregates of suspension cultures were composed of greenish, irregular, friable aggregates between 0.1 and $0.8 \mathrm{~mm}$ in diameter (Figure 3).

Figure 3. Suspension cell cultures of B. suaveolens after 4 weeks of inoculation, (a) In the $250 \mathrm{ml}$ size flasks bottom view, (b) Filtered cell aggregates on filter paper.
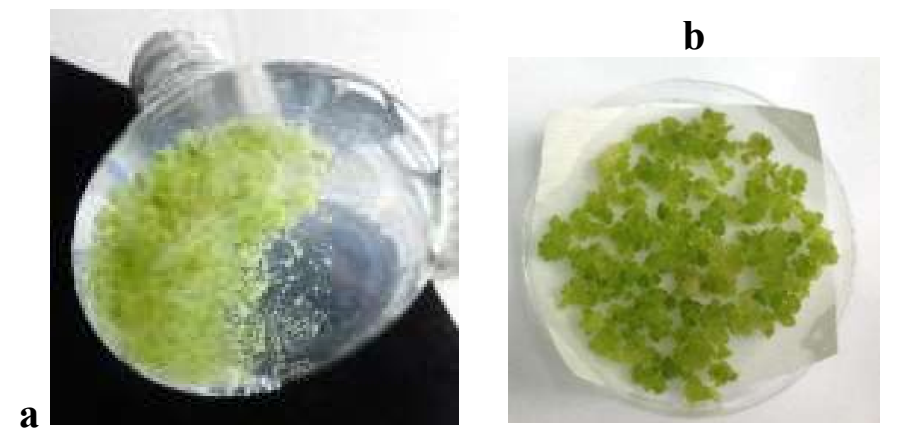

Biomass data (FW and DW) of the cell suspension cultures of $B$. suaveolens were maintained with different container sizes and medium amounts. The maximum mean biomass of $\mathrm{FW}$ $(4.85 \pm 0.46 \mathrm{~g} / \mathrm{culture})$ and DW $(0.4185 \pm 0.56 \mathrm{~g} / \mathrm{culture})$ were obtained in the $250 \mathrm{ml}$ size flask containing $1 / 8$ volume $(31.25 \mathrm{ml})$ of growth medium (Table 3$)$.

The flasks with $250 \mathrm{ml}$ size and with $1 / 5$ volume $(50 \mathrm{ml})$ of growth medium had the higher

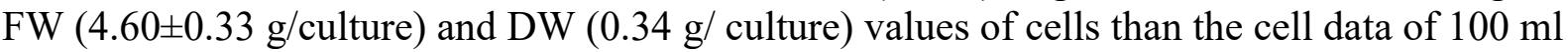
size flasks. The $12.5 \mathrm{ml}$ medium containing $100 \mathrm{ml}$ flasks produced a bit higher $\mathrm{FW}(3.63 \pm 0.58$ g) having cells than the high amount medium $(20 \mathrm{ml})$ containing flasks of the same size (FW: $3.44 \pm 0.24 \mathrm{~g}$ ). The same situation was observed with $250 \mathrm{ml}$ flask cultures. It is concluded that a low amount (1/8) of growth medium is more effective than a high amount (1/5) of growth medium in biomass production of cell suspension cultures. This biomass growth could be explained by the positive effect of high aeration in big culture containers on the shaker. The 
assessment of the results showed that the highest cell growth on callus and cell suspension cultures were obtained on the medium MS3 which was the best medium for callogenesis of $B$. suaveolens.

Table 3. Effects of container size and medium amount on growth parameters of B. suaveolens suspension cultures.

\begin{tabular}{cclccc}
\hline $\begin{array}{c}\text { Erlen Size } \\
(\mathrm{ml})\end{array}$ & $\begin{array}{c}\text { Medium } \\
(\mathrm{ml})\end{array}$ & Callus Morphology & $\begin{array}{c}\text { FW } \\
(\mathrm{g} / \text { culture })\end{array}$ & $\begin{array}{c}\text { DW } \\
(\mathrm{g})\end{array}$ & GI \\
\hline 100 & 12.5 & Greenish, friable & $3.62 \pm 0.58$ & $0.25 \pm 0.01$ & 2.62 \\
\hline 100 & 20 & Greenish, friable & $3.44 \pm 0.24$ & $0.28 \pm 0.00$ & 2.44 \\
\hline 250 & 31.25 & Greenish, friable & $4.85 \pm 0.46$ & $0.41 \pm 0.02$ & 3.85 \\
\hline 250 & 50 & Greenish, friable & $4.60 \pm 0.33$ & $0.34 \pm 0.00$ & 3.60 \\
\hline $100^{*}$ & 12.5 & Yellowish, compact & $2.98 \pm 0.25$ & $0.27 \pm 0.11$ & 1.98 \\
\hline $100^{*}$ & 20 & Yellowish, compact & $2.76 \pm 0.25$ & $0.34 \pm 0.51$ & 1.76 \\
\hline $250^{*}$ & 31.25 & Yellowish, compact & $3.62 \pm 0.24$ & $0.29 \pm 0.01$ & 2.62 \\
\hline $250^{*}$ & 50 & Yellowish, compact & $3.40 \pm 0.45$ & $0.30 \pm 0.03$ & 2.40 \\
\hline
\end{tabular}

Medium: MS3. Callus inoculum: $1 \mathrm{~g} /$ culture. ${ }^{*}$ PGRs free MS medium. Data are means $( \pm S E)$ of three repeats each with six replicates. Level of significance $p<.05$.

Comparing the biomass propagations of the semisolid and liquid cultures of B. suaveolens, the cell suspension culture system seems more promising. This is the first report on the establishment of the cell suspension cultures of $B$. suaveolens for tropane alkaloid production. To our knowledge, there is no previous report related to the cell suspension cultures of $B$. suaveolens. When compared to the overall plant system, cell suspension culture studies for the generation of secondary metabolites under controlled conditions are preferable. Plant growth regulators are important for the growth, development, and synthesis of secondary metabolites. Media composition, explant type, media strength, and presence of light have significant effects on in vitro plant development. These factors are critical for variation in biomass weight and production of secondary metabolites. Media strength was also assessed on callus induction of $B$. suaveolens that whole MS media promoted better callus growth than half-strength MS media in the presence of PGRs.

\subsection{Tropane Alkaloid Extraction from Plant Material}

The alkaloid extraction of the plant materials of B. suaveolens was performed efficiently as described in the material and methods section. After the chloroform washing step, a dark brown alkaloid extract was obtained and it was kept at $4{ }^{\circ} \mathrm{C}$ until further use. Chloroform extracts of the samples were applied onto the TLC plate and purity of scopolamine and atropine extracts were observed.

\subsection{Qualitative Analyses of Tropane Alkaloids}

The chloroform extract of leaf and alkaloid standards of atropine and scopolamine were spotted onto the silica TLC plate. The chromatography was performed in the related solvent system and the plate was sprayed with Dragendorff's reagent for the visualization of the spots. After spraying with the reagent, the plate was exposed to daylight and orange color spots of tropane alkaloids were appeared (Figure 4). Atropine (Figure 4A) and scopolamine (Figure 4B) spots of the leaf sample were observed clearly on the plate compared with the standard spots of atropine and scopolamine. This demonstrates that the modified alkaloid extraction protocol was effective for target alkaloid extraction of $B$. suaveolens. TLC technique is used in qualitative 
analyses for the initial screening of plant extracts for routine alkaloid analysis before more sophisticated instrumental chromatography analyses.

Figure 4. TLC chromatogram of alkaloid standards and extraction of B. suaveolens leaf sample: 1 . Atropin standard, 2. scopolamine standard, 3. Brugmansia leaf extract. Atropine band (A), scopolamine band (C), and other tropane alkaloid molecules $(\mathbf{B}, \mathbf{D})$. Crude extracts of Brugmansia leaf extract (4. and 5). The derivatizing agent is Dragendorff's reagent.
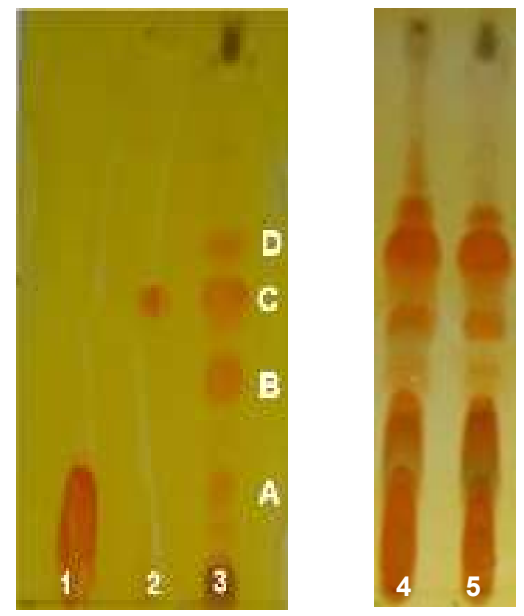

Qualitative estimation of the callus the leaf extracts of B. suaveolens was performed by HPLC (Figure 5). The atropine peak at the retention time of approximately 2.5 minutes was observed clearly. It was compared with literature data and concluded that the peaks between 1.25 and 2.0 min could be other alkaloids, most probably including scopolamine peak.

A linear calibration curve was obtained with a correlation coefficient $\left(\mathrm{r}^{2}\right)$ of 0.9977 . Based on the atropine standard curve, the percentages of atropine in total extracts of the leaf and callus were $66.52 \%$ and $55.78 \%$, respectively. The amounts of atropine obtained from the leaf and the callus were $18.87 \pm 0.19 \mathrm{mg} / \mathrm{g}$ dry weight and $6.94 \pm 0.19 \mathrm{mg} / \mathrm{g}$ dry weight, respectively. The callus has the capacity to biosynthesize atropine as the leaf. The results confirmed that atropine was produced in the callus of $B$. suaveolens as the major tropane alkaloid which resulted in $55.78 \%$ of total alkaloids. Several studies were performed to quantify tropane alkaloids in the Solanaceae family's plants. Atropa belladonna is the most known tropane alkaloid producer and the atropine amount was quantified in the leaves as $112.86 \mu \mathrm{g} / \mathrm{ml}$ (Koetz et al., 2017). Statistically, the results of the ANOVA showed that there were no significant differences among the treatments for FW and GI of the callus and cell suspension cultures (Table 2). The result is significant at $p<.05$.

\section{DISCUSSION and CONCLUSION}

The goal of this study was the establishment of in vitro growth systems of B. suaveolens and to improve the tropane alkaloid extraction technique from the leaf and the callus materials. The induction of callus cultures and establishment of cell suspension cultures of B. suaveolens were performed efficiently using different combinations of PGRs and the best growth medium was determined. B. suaveolens is not a widely known tropane alkaloid having species and not involved much in scientific studies. In addition, the extraction protocol of tropane alkaloids was modified efficiently, atropine and scopolamine were determined qualitatively and quantitatively using chromatography methods of TLC and HPLC.

According to the data obtained in this study, we can conclude that in vitro growth of $B$. suaveolens cells is promising for the production of main tropane alkaloids. In vitro culture systems with different strategies could be considered as an alternative source for the production of valuable phytochemicals. Further studies could focus on investigating atropine and 
scopolamine productivity of the cultures under scale-up conditions using elicitor and bioreactor. The results could serve as a background for the large-scale production of valuable alkaloids of $B$. suaveolens in vitro plant systems with improved strategie

Figure 5. HPLC chromatograms of (a) atropine as a standard alkaloid, (b) alkaloid extraction of the leaf sample, (c) alkaloid extraction of callus sample of B. suaveolens by UV-VIS detector at $210 \mathrm{~nm}$ at a with a flow rate of $1 \mathrm{ml} / \mathrm{min}$.

a

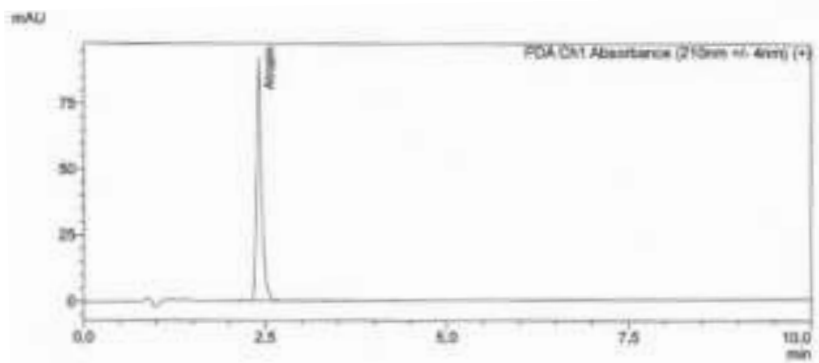

b
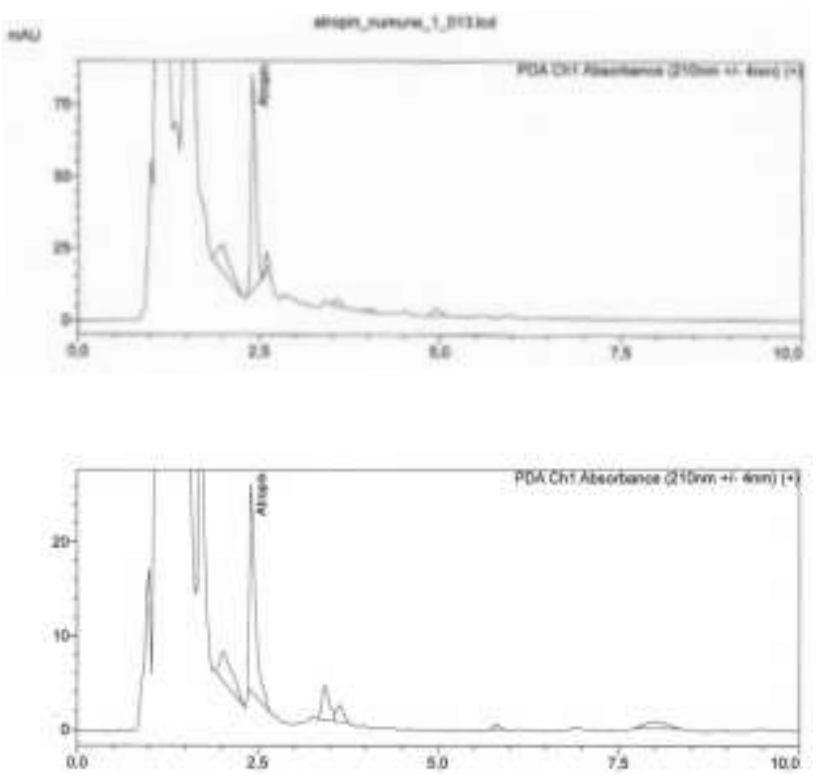

\section{Acknowledgments}

The authors would like to thank the students who worked previously in different stages of alkaloid extraction; Gülbahar Özge Alim, Tuğba Mutlu, and Tuğba Aydın. The authors would like to extend their gratitude to Şiringül Ay and Zeynep Özdemir for HPLC analyses. This study was a part of a project which was supported by the Scientific and Technological Research Council of Turkey (TÜBİTAK) with project number $117 \mathrm{H} 001$.

\section{Declaration of Conflicting Interests and Ethics}

The authors declare no conflict of interest. This research study complies with research and publishing ethics. The scientific and legal responsibility for manuscripts published in IJSM belongs to the author(s). Ethics Committee Number: The relevant publication was approved at the TUBITAK MAM GMBE's Ethics Committee Editorial Board meeting of 08.09.2020. 


\section{Authorship contribution statement}

Tijen Talas Ogras: Investigation, Plant resource, Plant based cultures, and Writing the manuscript. Elif Tahtasakal: Chemical extraction and purification methodology, and Formal Analysis. Selma Ozturk: Investigation, and Funding.

\section{Orcid}

Tijen Talas Oğraş (iD http://orcid.org/0000-0001-6608-8728

Elif Tahtasakal iD http://orcid.org/0000-0002-7793-8737

Selma Öztürk (iD http://orcid.org/0000-0002-7949-8993

\section{REFERENCES}

Alves, M.N., Sartoratto, A., \& Trigo J.R. (2007). Scopolamine in Brugmansia Suaveolens (Solanaceae): Defense, Allocation, Costs, and Induced Response. J Chem. Ecol., 33, $297-$ 309.

Anthony, S.J., Zuchowski, W., \& Setzer, W.N. (2009). Composition of the floral essential oil of Brugmansia suaveolens. Rec. Nat. Prod., 3, 76-81.

Baque, A., Moh, S. Lee, E., et al. (2012). Production of biomass and useful compounds from adventitious roots of high-value added medicinal plants using bioreactor. Biotechnol. Adv., 30, $1255-1267$.

Cardillo, A.B., Giulietti, A.M., Palazón, J. et al., (2013). Influence of hairy root ecotypes on production of tropane alkaloids in Brugmansia candida. Plant Cell Tiss. Organ Cult., 114, 305-312.

Chandran, H., Meena, M., Barupal, T., \& Sharma, K. (2020). Plant tissue culture as a perpetual source for production of industrially important bioactive compounds Biotechnology Reports, 26, e00450. https://doi.org/10.1016/j.btre.2020.e00450

Dandin, V.S., \& Murth, H.N. (2012). Enhanced in vitro multiplication of Nothapodytes nimmoniana Graham using semisolid and liquid cultures and estimation of camptothecin in the regenerated plants. Acta Physiol. Plant., 34, 1381-1386.

Dehghan, E., Hakkinen, S.T., Oksman-Caldentey, K.M., \& Ahmadi, F.S. (2012). Production of tropane alkaloids in diploid and tetraploid plants and in vitro hairy root cultures of Egyptian henbane (Hyoscyamus muticus L.). Plant Cell Tissue Organ Cult., 110, 35-44.

Dong, Y.S., Fu, C.H, Su, P., et al. (2015). Mechanisms and effective control of physiological browning phenomena in plant cell cultures. Physiol. Plant., 156, 13-28.

Ikeuchi, M., Sugimoto, K., \& Iwase, A. (2013). Plant callus: mechanisms of induction and repression. Plant Cell, 25, 3159-3173.

Ghorbanpour, M., Omidi, M., Etminan A., Hatami, M., \& Shooshtari, L. (2013). In Vitro Hyoscyamine and Scopolamine Production of Black Henbane (Hyoscyamus niger) from shoot tip culture under various plant growth regulators and aulture media. J. Trakia Science., 2, 125-134. Corpus ID: 30713657.

Kamada, H., Okamura, N., Satake, M., Harada, H., \& and Shimomura, K. (1986). Alkaloid production by hairy root cultures in Atropa belladonna. Plant Cell Rep., 5, 239-242. https://doi.org/10.1007/BF00269811

Koetz, M., Santos, T.G., Rayane, M., \& Henriques, A.T. (2017). Quantification of atropine in leaves of Atropa belladonna: development and validation of method by High Perfomance Liquid Chromatography. Drug Analytical Research, 1, 44-49. https://doi.org/10.22456/25 27-2616.74150

Lee, C.W.T., \& Shuler, M.L. (2000). The effect of inoculum density and conditioned medium on the production of ajmalicine and catharanthine from immobilized Catharanthus roseus cells. Biotechnol. Bioengr., 67, 61-71. 
Liu, J., Feng. H., \& Ma, Y. (2018). Effects of different plant hormones on callus induction and plant regeneration of miniature roses (Rosa hybrida L.). Horticult Int J., 2, 201-206. https://doi.org/10.15406/hij.2018.02.00053

Montanucci, C.A.R., Furlan, F., Neiverth, A.A., Neiverth, et al. (2012). Evaluation of seed germination and plant regeneration in Brugmansia suaveolens- a tropane alkaloid producer plant. International Journal of Medicinal and Aromatic Plants, 2, 396-405.

Murashige. T., \& Skoog, F. (1962). A revised medium for rapid growth and bioassays with tobacco tissue culture. Physiol Plant, 15, 473-497.

Pitta-Alvarez, S., Spollansky, T., \& Giulietti, A. (2000). The influence of different biotic and abiotic elicitors on the production and profile of tropane alkaloids in hairy root cultures of Brugmansia candida. Enzyme Microb. Technol., 26, 252-258. https://doi.org/10.1023/A:1 $\underline{005638029034}$

Praveen, N., Naik, P.M., Manohar, S.H. et al. (2009). In vitro regeneration of brahmi shoots using semisolid and liquid cultures and quantitative analysis of bacoside A. Acta Physiol Plant, 31, 723-728.

Sarin, R. (2005). Useful Metabolites from Plant Tissue Cultures. Biotechnology, 4, 79-93. https://scialert.net/abstract/doi=biotech.2005.79.93 